IZA DP No. 8904

Child Care Before Age Two and the Development of Language and Numeracy: Evidence from a Lottery

Nina Drange

Tarjei Havnes

March 2015 


\title{
Child Care Before Age Two and the Development of Language and Numeracy: Evidence from a Lottery
}

\author{
Nina Drange \\ Statistics Norway \\ Tarjei Havnes \\ University of Oslo \\ and IZA
}

Discussion Paper No. 8904

March 2015

IZA

P.O. Box 7240

53072 Bonn

Germany

Phone: $+49-228-3894-0$

Fax: +49-228-3894-180

E-mail: iza@iza.org

Any opinions expressed here are those of the author(s) and not those of IZA. Research published in this series may include views on policy, but the institute itself takes no institutional policy positions. The IZA research network is committed to the IZA Guiding Principles of Research Integrity.

The Institute for the Study of Labor (IZA) in Bonn is a local and virtual international research center and a place of communication between science, politics and business. IZA is an independent nonprofit organization supported by Deutsche Post Foundation. The center is associated with the University of Bonn and offers a stimulating research environment through its international network, workshops and conferences, data service, project support, research visits and doctoral program. IZA engages in (i) original and internationally competitive research in all fields of labor economics, (ii) development of policy concepts, and (iii) dissemination of research results and concepts to the interested public.

IZA Discussion Papers often represent preliminary work and are circulated to encourage discussion. Citation of such a paper should account for its provisional character. A revised version may be available directly from the author. 


\title{
ABSTRACT
}

\section{Child Care Before Age Two and the Development of Language and Numeracy: Evidence from a Lottery ${ }^{*}$}

\begin{abstract}
Young children are thought to be vulnerable to separation from the primary caregiver/s. This raises concern about whether early child care enrollment may harm children's development. We use child care assignment lotteries to estimate the effect of child care starting age on early cognitive achievement in Oslo, Norway. Getting a lottery offer lowers starting age by about four months, from a mean of about 19 months in the control group. Lottery estimates show significant score gains for children at age seven. Survey evidence and an increase in labor supply of both mothers and fathers following the offer, suggest that parental care is the most relevant alternative mode of care. We document that the assignment lottery generates balance in observable characteristics, supporting our empirical approach.
\end{abstract}

JEL Classification: $\quad$ I21, J13

Keywords: $\quad$ early child care, child development

Corresponding author:

Tarjei Havnes

Department of Economics

University of Oslo

Box 1095 Blindern

0317 Oslo

Norway

E-mail: tarjei.havnes@econ.uio.no

\footnotetext{
* Thanks to Oslo Municipality for generously providing data, institutional detail and feedback on the project, in particular to Eli Aspelund, Thomas Bang and Ragnhild Walberg at HEV. The project received financial support from the Norwegian Research Council (Grant Number 212305 and Grant Number 236947). The project is also part of the research activities at the ESOP center at the Department of Economics, University of Oslo. ESOP is supported by The Research Council of Norway (grant no. 179552).
} 


\section{Introduction}

Child care enrollment of toddlers has increased in many countries over the last decade. In 2010, the enrollment of children below age two stood at $43 \%$ in the United States, and at $33 \%$ in OECD countries, up from $20 \%$ in 2003. In several countries, enrollment is much higher, with rates above $50 \%$ in countries like Denmark, Korea, the Netherlands and Norway. ${ }^{1}$ At the same time, there is concern among both researchers and policymakers that separation from the primary caregiver, typically the mother, may cause stress and anxiety in the child, with potentially adverse effects on childrens development [Bowlby, 1969, Mercer, 2006]. ${ }^{2}$ Yet, evidence on how child care affects the development of toddlers is largely missing. ${ }^{3}$ This is worrying for policymakers, because programs are often heavily subsidized, but also for parents who need to decide whether and when to enroll their children in child care.

In this paper, we provide first evidence on the impact of child care enrollment for children age 1-2 years old (henceforth toddlers), on their cognitive performance in language and mathematics at age seven. Determining the impact in this age group is of key importance, both because enrollment rates are increasing at a strong rate and because children are thought to be particularly vulnerable during this period. For identification, we exploit a randomized lottery used by the city government in the Norwegian capital Oslo in order to allocate offers of child care places when child care institutions are over-subscribed, similar to the strategy used by Abdulkadiroglu et al. [2011]. This should provide variation in child care starting age that is as good as random. Indeed, we document that the allocation mechanism generates balance in observable characteristics, supporting our empirical approach. Armed with unique data on all applicants, offers and enrollment, as well as performance tests in language and mathematics at age seven, we use the randomized offer of a public child care slot as an instrumental variable for the age of the child when he or she first attends child care. Specifically, we consider cohorts born 2004-2006, among whom there was substantial oversubscription of toddlers to child care institutions in Oslo.

Our results show that children who randomly get an offer of public child care perform better on both the language test (0.12 SD) and the mathematics test (0.12 SD) at age 6-7. Next, while children that get an offer first attend child care at about 15 months of age on

\footnotetext{
${ }^{1}$ Source: OECD Family data base.

${ }^{2}$ Bowlby [1969] defines the attachment phase as the period when the child is from 6-8 months to 24 months old. The age period we study in this paper is largely around 12-24 months.

${ }^{3}$ We are aware of only one other study that estimates how child care affects the development of toddlers. Felfe and Lalive [2014] estimate marginal treatment effects of child care attendance before age three using county level variation in child care coverage rates in West Germany. They find positive impacts of child care on the youngest children, boys, and children from low SES families. A related strand of literature may indirectly reflect the effects of child care attendance in looking at the effect of parental leave policies on child outcomes (e.g. Dustmann and Schønberg [2012], Liu and Skans [2010], Carneiro et al. [2015]). The alternative to parental care in most of this studies is, however, likely to be informal and not formal sources of care.
} 
average, children who randomly do not get an offer first attend at about 19 months of age on average. Among children delayed, about two thirds start a full year later. When we estimate the impact of child care starting age using the lottery offer as an instrumental variable, we find that starting child care one month earlier causes an improvement in test scores of $0.027 \mathrm{SD}$ and $0.028 \mathrm{SD}$ in language and mathematics, respectively.

Because the distribution of the test score we consider is skewed, we must be careful when interpreting the economic significance of our estimates. One way to do this is to compare our estimates to the gaps in test scores that we observe between well defined sub-groups of the population. For instance, the estimated impact of getting an offer corresponds to about the average gap in test performance between boys and girls, or to between $30 \%$ and $40 \%$ of the performance gap between children of low and high educated parents. One should keep in mind, though, that the test scores we consider are essentially truncated at the top, which means that the observed gaps are likely smaller than what we would observe with more symmetrically distributed test scores.

One important argument for why governments want to subsidize child care, is that they can help counter differences in school readiness between children from different socioeconomic backgrounds. When estimating in subgroups, our evidence partly supports this case: We find stronger effects of early child care start among children from low income families, and no impact among high income families in neither language nor mathematics. This suggests that child care policies may be more effective if targeted at low income households.

Our results on how child care affects the development of toddlers complement the growing recent literature on how child care institutions affect the development of preschool age children. ${ }^{4}$ The literature is divided in two distinct branches, one focussed on targeted programs, and another focussed on universal programs available to the general population. While studies of targeted programs often find positive effects, ${ }^{5}$ the literature on universal programs is smaller and findings are mixed. ${ }^{6}$ Perhaps as a consequence, the discussion on child care policies is based largely on the targeted literature and descriptive evidence, even when the policies considered are universal. In contrast, we study the impact of a

\footnotetext{
${ }^{4}$ For recent reviews, see Almond and Currie [2010], Ruhm and Waldfogel [2011], or Baker [2011].

${ }^{5}$ The Perry Preschool and Abecedarian programs are examples of targeted randomized programs (see Barnett [1995] and Karoly et al. [2005] for surveys of the literature.), while the US Head Start program provides an example of a targeted non-randomized program (see e.g. Currie [2001] or McKey et al. [1985] for a review of the findings). While the picture is somewhat mixed, the most robust evidence on Head Start tends to show positive effects on long-run outcomes such as high school dropout, college attendance and crime [Currie and Thomas, 1995, Garces et al., 2000, Ludwig and Miller, 2007, Deming, 2009].

${ }^{6}$ Several studies from Canada show a negative impact on a variety of child outcomes [Baker et al., 2008, Lefebvre and Merrigan, 2008a, DeCicca and Smith, 2013], while Cascio [2009] and Gupta and Simonsen [2010] find essentially no impact from child care programs in the US and Denmark, respectively. In contrast, positive impacts on a number of outcomes are found from child care programs in several countries, including the US [Fitzpatrick, 2008], Uruguay [Berlinski et al., 2008], Norway [Havnes and Mogstad, 2011b, 2014], Germany [Dustmann et al., 2013, Felfe and Lalive, 2014], and Spain [Felfe et al., 2015].
} 
universally available program among applicants that are explicitly not prioritized in child care.

In studies of how child care affects child development, it is crucial to shed light on the alternative mode of care that children would have been exposed to if they did not attend child care. Typically, one considers three alternatives: Parental care, formal child care and other, more informal, sources of care [Blau and Currie, 2006]. To investigate the counterfactual mode of care for children who get an offer of a public child care slot, we start by considering survey data on stated demand and actual use for the population of parents with toddlers. While about $70 \%$ of parents state demand for child care, either full time or part time, only $33 \%$ actually have their children enrolled in child care. In comparison, while $56 \%$ of parents say that they care for their children themselves, only $17 \%$ actually prefer to do so. This suggests that parental care is the dominant alternative for Norwegian toddlers in general.

To get an estimate of the importance of parental care as the counterfactual in our particular sample, we next consider the impact of getting an offer of a public child care slot on parents labor supply. Results suggest that the offer increases labor supply of both mothers and fathers. While mothers labor supply increases around the margin of full time employment, fathers labor supply increases mostly at the top. This is consistent with parents responding to the offer by reducing the position of mothers and the work hours of fathers, as suggested by anecdotal evidence. This evidence contrasts previous findings for preschool aged children in Norway, where effects on parental labor supply have been estimated to be quite weak [Havnes and Mogstad, 2011a]. ${ }^{7}$ At the same time, this may not come as a surprise, since parents of preschool children may both have stronger options in the informal market and be more willing to use them, compared to parents of toddlers. Also, our estimates relate to the mid-2000s, while Havnes and Mogstad [2011a] estimate the impact of the introduction of child care in Norway from the late 1970s. With much higher employment rates of Norwegian women in recent years, informal sources of care may well be less available.

The paper proceeds as follows. We first discuss the institutional background in Section 2. Section 3 presents and discusses our empirical approach, before Section 4 describes our data. Section 5 presents our main results, including discussions on heterogeneous impacts and mechanisms, while section 6 concludes.

\footnotetext{
${ }^{7}$ Evidence from other countries is mixed. In a survey of the early literature, Blau and Currie [2006] report elasticities of maternal employment with respect to the price of child care ranging from 0 to -1 . More recently, Baker et al. [2008] find a positive effect on maternal labor supply following the introduction of heavily subsidized universally available child care in Quebec. Meanwhile, Lundin et al. [2008] find no such effect when studying a childcare reform which capped childcare prices in Sweden. See also Schlosser [2005], Cascio [2009], Havnes and Mogstad [2011b], Lefebvre and Merrigan [2008b] and Berlinski and Galiani [2007]. For a review of the literature, see Blau and Currie [2006].
} 


\section{Institutional background}

In this section, we provide brief instititutional background about care of young children in Norway, with a focus on the child care sector.

Parental leave. In 2005, Norwegian parents were entitled to 43 weeks of parental leave with full wage compensation (alternatively 53 weeks with $80 \%$ compensation). ${ }^{8}$ This was expanded to 44 (54) weeks in 2006. Parents are further entitled to one year each of unpaid leave in immediate continuation of regular parental leave. In practice, most parents can thus stay at home with their newborn for about a year.

Structure and content of child care in Norway. To help interpret our results, we must understand the type of care we are studying. Child care in Norway is heavily regulated, with provisions on staff qualifications, number of children per adult and per teacher, size of play area, and educational orientation. Institutions are run by an educated preschool teacher responsible for day-to-day management and educational content. The pre-school teacher education is a one year college degree, including supervised practice in a formal child care institution. The head teacher is responsible for planning, observation, collaboration and evaluation of all activities. The head teacher is also responsible for communication and collaboration with parents and local authorities, including health stations and child welfare services when necessary. Child care regulations specify that there should be at least one educated pre-school teacher per 10 children aged below three. In addition, regulations specify that there should be one adult per three children below three, including the teacher. There is no educational requirements for the additional staff. In Oslo, about $60 \%$ of child care institutions are public, while the remaining are privately operated. Both public and private institutions require municipal approval and supervision to be entitled to federal subsidies that cover around $80 \%$ of costs. Since 2003, parental copayment is capped at around 2,500 NOK per month for a full time slot. Child care institutions are typically open from around 7.30 am to $5 \mathrm{pm}$.

In terms of educational content, a social pedagogy tradition has dominated child care practices in Norway since its inception in the 1970s. According to this tradition children should develop social, language and physical skills mainly through play and informal learning. ${ }^{9}$ The informal learning is typically carried out in the context of day-to-day social interaction between children and staff, in addition to specific activities for different age groups.

\footnotetext{
${ }^{8}$ This entitlement is conditional on maternal employment during at least six of the ten months before the birth. About $85 \%$ of new mothers satisfy this requirement (NOU 2012:15). Remaining parents are entitled to unpaid parental leave with employment protection, and receive a one-time payment of about 35,000 NOK.

${ }^{9}$ The social pedagogy tradition to early education has been especially influential in the Nordic countries and Central-Europe. In contrast, a so-called pre-primary pedagogic approach to early education has dominated many English and French-speaking countries, favoring formal learning processes to meet explicit standards for what children should know and be able to do before they start school.
} 
In table 1, we report some institutional characteristics of the institutions in our sample. We see that an average institution in our sample services 17 children aged 0-2, with about three adults per ten children, including one teacher, in line with federal regulations. The minority share among all children in the institution is about $25 \%$, reflecting the high share of children with a minority background residing in Oslo. The enrollment of children with an immigrant background is, however, very low for children below three years of age [Drange and Telle, 2015]. Note that this implies that our results should be interpreted to reflect the impacts on native children.

Table 1: Institutional characteristics

\begin{tabular}{lccc}
\hline & Mean & SD & N \\
\hline Teacher/children & .077 & .026 & 236 \\
No. of adults & 15.4 & 7.6 & 262 \\
Adult / children & .298 & .068 & 236 \\
Minority share & .256 & .207 & 236 \\
No. of children 0-2 & 17.1 & 10.7 & 262 \\
\hline
\end{tabular}

Source: The child care register, Statistics Norway.

Child care centers in Norway in an international perspective. The provision of child care in Norway bears resemblance with the other Nordic countries with relatively high public subsidies. ${ }^{10}$ However, the enrollment of children below 3 in Norway in 2004 was $44 \%$, substantially lower than for example Denmark with an enrollment at $83 \%$. This is comparable to US enrollment which stood at $38 \%$ for this age group at the time [OECD, 2006].

\section{Empirical strategy}

We are interested in the effect of early child care enrollment on childrens cognitive performance, and follow closely the approach in Abdulkadiroglu et al. [2011]. Because the effects of enrollment are likely to depend on the age at which the child first attends child care, we start with the following outcome equation,

$$
y_{i t}=\gamma A G E_{i t}+X_{i t}^{\prime} \beta+\epsilon_{i t}
$$

where $t$ denotes the cohort, and $A G E_{i t}$ is the age of the child in months when he or she first attends any child care institution, public or private. $X_{i t}$ are a set of socio-demographic

\footnotetext{
${ }^{10}$ For children below three years old parental contribution in the Nordic countries varied from 9-15\% compared to an OECD average of $25-30 \%$ in the mid 2000. In 2003, the state subsidy to a child care slot for a child below three was 9,773 EURO annually in Norway [OECD, 2006].
} 
characteristics of the child and parents, measured the year before the child was born. ${ }^{11}$

Because enrollment in child care is likely determined in part by parental preferences and child innate characteristics, starting age is likely to be correlated with unobserved determinants of cognitive performance. For instance, we might expect more able parents to be more closely tied to the labor market, and therefore enroll their children in child care earlier. If so, then we may expect that children who are enrolled early would perform better in any case. On the other hand, we might expect more child-centered parents to enroll their children in child care later. If so, being enrolled early could be a marker for a poor home environment, which would suggest that these children should perform worse. This implies that estimation of equation (1) will give biased estimates of the impact of child care starting age on cognitive performance.

To circumvent this problem, we take advantage of an assignment lottery used by the Oslo city administration to distribute offers to applicants when institutions were oversubscribed. Each year, the vast majority of available child care slots in both public and private institutions are allocated in a centralized allocation round. The application deadline is around March 1 of each year, for enrollment in mid-August. Parents may apply for placement in up to seven child care centers in their application, and may list both public and private institutions.

Allocation takes place inside the city district of residence, but available slots may be allocated to children from other city districts after the main allocation round. Children may be awarded priority placement if they have, for instance, a sibling in the same child care instititution or are disabled. In our sample, $24 \%$ of children get priority placement. Children that have their first birthday after September 1 are not included in the main allocation round, but may receive offers after this round is over. In our analysis we exclude both of the former groups, to focus on the main group of children that are included in the main allocation round without being assigned priority.

Based on the applications received, the municipality generates lists of non-priority applicants to each institution. Lists for private instititutions are transmitted to the institutions, which handle their own admissions based on these lists along with full details of the individual child and application. In line with Abdulkadiroglu et al. [2011], we therefore exclude from our analysis children that have a private institution ranked first on their application.

The mechanism for assignment to public institutions resembles a serial dictatorship: The order of children on the full list of applicants to each public institution is randomized in the computer before they are presented to the city official. Available slots are then allocated according to the random rank on the application list, and offers are sent to

\footnotetext{
${ }^{11}$ Child characteristics include gender, month of birth and birth order. Parental characteristics include dummy variables for full time work, receipt of social assistance, high school completion, college degree, missing parental education, and missing parent identifier.
} 
parents. Parents may accept or reject the offer. If they reject, the offer is conferred to the highest ranked child on the application list who did not already get an offer at this or some other institution. Once a child receives an offer for a child care place, the child is taken out of the lists to other institutions to which it applied. The child may, however, maintain their application to the first ranked institution. This along with the upper limit on institutions on the list could raise concern about strategic application behavior, but we find no suggestions of this below.

The main allocation round ends each year around June 1. After the main allocation round, available slots may be offered to any applicant, whether or not they ranked the institution on their application. This process is largely at the discretion of the city officials or even child care managers, and is therefore susceptible to manipulation. We therefore use only offers dated before June 1 each year in our analysis.

To help identify the effect of early child care enrollment, we use an IV strategy, where we let the offers generated in the assignment lottery act as instruments for child care starting age. Specifically, we specify our IV-model as follows, where equation (2) is the second stage and equation (3) is the first stage.

$$
\begin{aligned}
y_{i t} & =\gamma A G E_{i t}+\sum_{k} \alpha_{k t} D_{k i t}+X_{i t}^{\prime} \beta+\epsilon_{i t} \\
A G E_{i t} & =\pi O F F E R_{i t}+\sum_{k} \eta_{k t} D_{k i t}+X_{i t}^{\prime} \psi+\omega_{i t} .
\end{aligned}
$$

where $O F F E R_{i t}$ is a dummy equal to one if the child received an offer of a public child care place generated in the assignment lottery. In both the first and second stage, residuals are clustered at the level of the first choice institution. Following Abdulkadiroglu et al. [2011], we also include indicators for lottery-specific risk sets $D_{k i t}$ to account for the fact that children apply to different institutions with different numbers of applicants and available slots. The extent of oversubscription determines the probability of receiving a lottery offer. If oversubscription rates are correlated with, for instance, the quality of the child care institution, and applying to good institutions in turn is correlated with unobservable traits that determine cognitive performance, then a comparison based on lottery offers may give biased estimates of the impact on cognitive performance of early child care enrollment. To guard against such bias, we control for the number and identity of institutions to which an applicant applied. ${ }^{12}$

In order for random offers to be relevant, we need to have over-subscription of toddlers to child care institutions. This is determined by the number of non-priority applicants per remaining available slot after priority placements. Table 2 shows descriptive statistics

\footnotetext{
${ }^{12}$ Specifically, the risk set includes a full set of dummy variables for each institution by year, so that for each institution and year there is a dummy equal to one if child $i$ applied to that institution in that year and zero otherwise. In addition, the risk set includes dummy variables for the number of applications by year.
} 
Table 2: Applications, places and oversubscription in child care institutions in the centralized admission process in Oslo, 2005-2007.

\begin{tabular}{lcccc}
\hline & Mean & SD & Min & Max \\
\hline \hline No. of places & 6.21 & 4.75 & 0 & 33 \\
No. of applicants & 50.75 & 30.49 & 1 & 165 \\
Applicants - Places & 44.55 & 29.47 & 1 & 158 \\
Applicants / Places & 11.91 & 11.56 & 1.5 & 109 \\
\hline
\end{tabular}

for the number of available slots, the number of applicants and oversubscription to child care institutions in Oslo in the period we consider. Oversubscription is both strong and widespread: The mean number of applicants to each child care slot is just under 12, while the median is nine. This is mirrored in the fact that only $27 \%$ of the children in our sample get an offer in the assignment lottery, and in the strong first stage estimates documented below.

The validity of the lottery offer as an instrument for child care starting age, relies on the quality of the assignment lottery. While the city administration ensures us that the lottery was randomized by a computer algorithm, as described earlier, there is always the possibility that the randomization failed, or that there was manipulation between the actual randomization and the sending out of offers. To verify that the randomization was successful, the first four columns of Table 3 reports means and standard deviations of background characteristics for children in our estimation sample, separately by whether the child received an offer or not. Table 3 shows that the two groups look well balanced. We also test this formally in the context of our econometric model, by regressing the offer dummy on all characteristics, controlling for the risk sets. The final column of Table 3 reports $t$-statistics of the individual coefficients from this regression, which are usually very low. In a joint test of whether coefficients on all covariates are equal to zero, we get an $F$-value of 1.22 , confirming that the two groups are indeed well balanced. 
Table 3: Balance in background characteristics between children with and without a lottery offer.

\begin{tabular}{lccccc}
\hline & \multicolumn{2}{c}{ No offer } & \multicolumn{2}{c}{ Offer } & $t$-value \\
\hline \hline Girl & 0.497 & 0.500 & 0.523 & 0.500 & 0.11 \\
Age & 14.115 & 1.949 & 14.163 & 2.017 & 1.06 \\
Immigrant & 0.10 & 0.300 & 0.096 & 0.295 & -1.34 \\
Mother & & & & \\
- years of educ. & 14.793 & 3.060 & 14.731 & 2.923 & 0.69 \\
- earnings & 297323 & 162341 & 292643 & 159379 & 0.67 \\
- age & 33.559 & 4.3749 & 33.386 & 4.439 & -2.09 \\
- age first birth & 29.900 & 4.5291 & 29.860 & 4.580 & 0.77 \\
Father & & & & & \\
- years of educ. & 14.532 & 3.460 & 14.417 & 3.554 & -0.07 \\
- earnings & 428276 & 388353 & 427315 & 447764 & 0.71 \\
- age & 35.512 & 6.337 & 35.128 & 7.328 & 1.71 \\
- age first birth & 31.552 & 5.880 & 30.822 & 6.474 & -0.60 \\
\hline \multicolumn{2}{c}{$N=1,425$} & \multicolumn{2}{c}{$N=585$} & $F=1.22$ \\
\hline
\end{tabular}

Note: The table reports means and standard deviations of covariates by whether the child received an offer in the assignment lottery. The final column reports $t$-statistics of the individual coefficients from a regression of the offer dummy on all characteristics, controlling for the risk sets, and the $F$-statistic from a joint test of whether coefficients on all covariates are equal to zero. Age refers to the age in months of the child in August of the year of application. Earnings are pensionable income from work and self-employment. Detailed descriptions of the background characteristics are provided in 4 .

\section{Data}

Data. Our data are based on several different administrative registers from the Oslo city government and Statistics Norway. Firstly, we have access to the municipal database used in the centralized application system for child care in Oslo. This provides information on applications for and enrollments in virtually all child care institutions in Oslo for the years 2005-2010, including both public and private child care institutions. Applicants that list several institutions in their applications are registered as separate coincident applications. The database also provides information about offers of slots in public child care centers. Applications, enrollment and offers are recorded with date of receipt, date of first attendance and date the offer was made, respectively.

Second, we have access to a database with information about performance on tests made available by the school authority in Oslo municipality. This provides information about enrollment in primary school and score on performance tests in Norwegian language and mathematics, conducted in April of first grade. The tests are designed nationally, and are intended to help identify underperforming children, enabling schools to allocate resources to these children. The language test maps the ability to write letters, recognize 
written letters, identify spoken letters, combine sounds, write words, read words and read sentences. The mathematics test maps the ability to count, to compare numbers, to rank numbers, to recognize sequences of numbers, to count forward and backward from a given number, to split a number into two other numbers (i.e. $4=1+\ldots$ ), to solve textual assignments and to add two numbers. We provide further detail on these tests in the appendix.

Each test is scored on a relatively fine scale, where students may score from zero to 105 in language, and zero to 50 in mathematics. Because tests are designed to identify children with problems, test score distributions are skewed, ${ }^{13}$ with about ten and $15 \%$ of children in our sample getting the top score in language and mathematics, respectively. This is important to keep in mind when interpreting our results.

In our analysis, we consider two outcomes from each test. First, we normalize the scores to have mean zero and standard deviation equal to one. Second, we use dummy variables for performance below a nationally determined threshold. Thresholds are set for individual parts of each test from a trial of the test on a panel of children, conducted prior to actual testing each year. The thresholds are intended to identify the bottom 15-20\% of children. From these we define the dummy variables Below threshold equal to one if the child has one or more test parts with scores below the threshold, and zero otherwise, separately for language and mathematics. Finally, as a summary measure of cognitive skills, we also consider the unweighted average of the standardized test scores in language and mathematics.

Third, we can link both databases to rich Norwegian administrative registers available from Statistics Norway, with individual information on demographics (e.g. sex, age, immigrant status, marital status, number of children), socioeconomic status (e.g. years of education, income, employment status), and residence. Income and employment data are collected from tax records and other administrative registers. The household information is from the Central Population Register, which is updated annually by the local population registries and verified by the Norwegian Tax Authority. We also have access to national registry data on municipal child care coverage reported by the child care institutions themselves. The reliability of Norwegian register data is considered to be very good, as is documented by the fact that they received the highest rating in a data quality assessment prepared for the OECD by Atkinson et al. [1995]. Importantly, all data sources contain personal identifiers that allow us to link individuals across all registers.

Estimation sample. We start with the universe of children born $2004-2006,{ }^{14}$ for whom parents apply for a child care slot in Oslo for the first time the calender year they turn one

\footnotetext{
${ }^{13}$ Appendix figure (A1) draws the distribution of test scores in our sample.

${ }^{14}$ Due to a restrictive storage policy in the municipality, data on children born in January and February 2004 were deleted from the application data base before we got access to it. We are therefore not able to include these children in our sample.
} 
Table 4: Performance in language and mathematics tests at age seven for children with and without a lottery offer.

\begin{tabular}{lcccc}
\hline & \multicolumn{2}{c}{ No offer } & \multicolumn{2}{c}{ Offer } \\
\hline \hline Average score & 71.84 & $(8.10)$ & 72.49 & $(7.00)$ \\
Language & 98.90 & $(11.26)$ & 99.75 & $(8.95)$ \\
- below limit & 0.132 & $(0.339)$ & 0.118 & $(0.323)$ \\
Mathematics & 44.78 & $(6.55)$ & 45.24 & $(6.31)$ \\
- below limit & 0.067 & $(0.251)$ & 0.055 & $(0.228)$ \\
Starting age (months) & 18.88 & $(8.06)$ & 15.03 & $(4.59)$ \\
\hline
\end{tabular}

Note: Offer are children that received an offer in the assignment lottery, while No offer are children that did not receive an offer in the assignment lottery, see Section 3.

year old. Because our identification comes from offers of public child care slots, we focus attention on children with a public institution on the first rank, while we allow both private and public institutions on ranks 2-7. As discussed above, we also exclude children who had priority in child care or who turn one after September 1 in the application year, since our identification does not influence these children. We finally exclude a handful of children with missing values on our dependent variables, and a handful of children registered as starting in child care before ten months old. Rather than excluding children with missing values on control variables, we construct dummy variables for missing and include these in our regressions. Our final estimation sample then consists of 2,010 children.

\section{$5 \quad$ Empirical results}

We now turn to our main analysis of how early enrollment in child care affected the cognitive performance of children at age seven. We start by a reduced form analysis, where we compare outcomes of children who got a lottery offer to children who did not get a lottery offer. Table 4 shows means and standard deviations of our main outcome variables and our key explanatory variable, child care starting age. The mean test scores show that children who receive a lottery offer perform about eight to nine percent of a standard deviation better than children who do not receive a lottery offer. Meanwhile, just over $12 \%$ of children are below the threshold for low performance in language, while about six percent are below the threshold in mathematics. In both subjects, the mean child who got a lottery offer performs about half a point better than the mean child who did not get a lottery offer, and are about 1.5 percentage point less likely to score below the threshold for low performance. This is first evidence that early child care enrollment has a positive impact on childrens cognitive development.

Next, we consider this reduced form model formally, by estimating the impact of getting an offer on test performance, controlling for risk sets as in equation (3). We 
Table 5: Estimates of the impact of a lottery offer on performance in language and mathematics.

\begin{tabular}{lccccc}
\hline & \multicolumn{2}{c}{ No controls } & \multicolumn{2}{c}{ With controls } & Mean \\
& $b$ & $S E$ & $b$ & $S E$ & \\
\hline \hline Average score & 0.121 & $(0.064)$ & 0.105 & $(0.061)$ & 0.000 \\
Language & 0.118 & $(0.076)$ & 0.104 & $(0.074)$ & 0.000 \\
- below limit & -0.025 & $(0.024)$ & -0.028 & $(0.023)$ & 0.128 \\
Mathematics & 0.124 & $(0.066)$ & 0.106 & $(0.062)$ & 0.000 \\
- below limit & -0.023 & $(0.014)$ & -0.020 & $(0.014)$ & 0.064 \\
\hline
\end{tabular}

Note: Effects are reported as percent of the standard deviation. Standard errors are heteroskedasticity robust and clustered at the first choice institution level. All regressions include a risk set with a full set of dummy variables for each institution by year and the number of child care institutions listed. We also include cohort fixed effects. Column 2 reports estimates without covariates whereas column 4 reports estimates including the controls listed in Table 3.

report estimates both including and excluding covariates. While including covariates should not change our estimates when the explanatory variable of interest is as good as random, it may be helpful to improve precision in our estimates. Results reported in Table 5 clarify our observations from above, and indicate that getting a lottery offer improved the average performance of children by about $12 \%$ of a standard deviation. This effect was driven both by an improvement in language of about $12 \%$ of a standard deviation, and by an improvement in mathematics of about the same magnitude.

Table 6 reports estimates from our full IV-model, where the receipt of a lottery offer is used to instrument for the age at first attendance in a child care institution. The two last rows of the table report estimates from our first stage equation, and show that the lottery offer decreased starting age by about four months on average. The $F$-statistic on the instrument is about 100, which implies that we need not worry about problems associated with weak instruments. To understand more in detail how getting a lottery offer affects child care starting age, Figure 1 shows the cumulative distribution of children having started child care at different ages. While $91 \%$ of children who received an offer had started child care by 18 months old, this was the case for only $65 \%$ of the comparison group. Among those children who were delayed, more than two thirds started a full year later; $96 \%$ (99\%) of children who received an offer had started child care by 24 (36) months old, compared to $77 \%$ (95\%) in the comparison group.

Turning now to the IV-estimates in Table 6, the estimates without controls suggests that starting child care one month later causes a drop in school performance of just under three percent of a standard deviation. This is driven by a drop in both the language score and the mathematics score of just under 0.03 SD. All of these estimates are significant at the five percent level. When we consider the impact on the probability of scoring below the limit for low performance, we find an impact of around 0.6 percentage points on both tests. As expected from the above balancing analysis, estimates barely move when we 


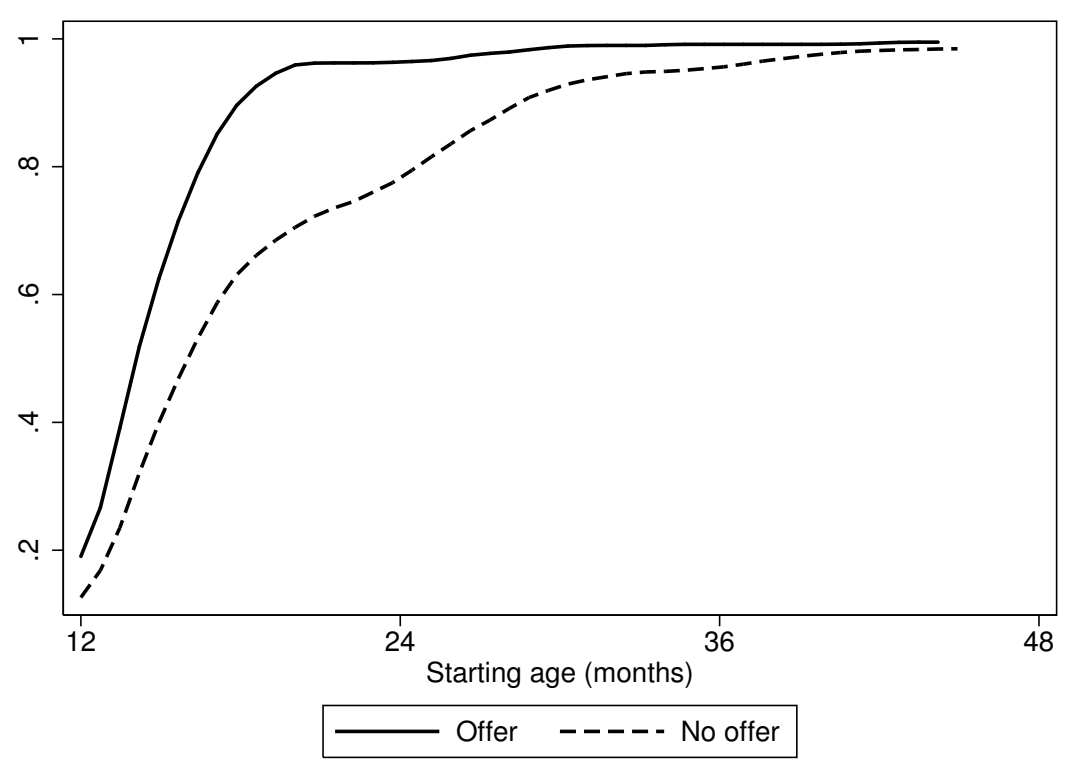

Figure 1: Cumulative distribution of age at child care start for children with and without a lottery offer.

include covariates.

To understand the economic significance of changes in test scores is in general somewhat difficult, because they do not have a meaningful cardinal scale [Cunha and Heckman, 2008]. This may be particularly true in our case, where the distribution of the test score is skewed, and quite different from the often bell-shaped test scores considered in the literature. Though comparisons of estimates across different test score outcomes is always risky, this means that it could be particularly misleading to compare our estimates directly to those found in other studies.

To interpret our estimates, we need to map them into a metric that is more easily interpretable in other contexts. One way to do this is to compare our estimates to the gaps in test scores that we observe between well defined sub-groups of the population. For instance, the average gender gap in performance between boys and girls in our sample is about 0.12 SD on both the language and the mathematics test (cf. table 7 below). Our estimates suggest, therefore, an improvement comparable to the gender performance gap when a child gets a lottery offer. In mathematics, winning the lottery is predicted to improve performance by about $0.12 \mathrm{SD}$, which correspondsto between 30 and $40 \%$ of the performance gap between children of low and high educated parents. Remember, though, that the test scores we consider are essentially truncated at the top here, so the observed gaps are likely smaller than what we would observe with more symmetrically distributed test scores. 
Table 6: IV-estimates of the impact of child care starting age on performance in language and mathematics.

\begin{tabular}{|c|c|c|c|c|c|}
\hline & \multicolumn{2}{|c|}{ No controls } & \multicolumn{2}{|c|}{ With controls } & \multirow{2}{*}{ Mean } \\
\hline & $b$ & $S E$ & $b$ & $S E$ & \\
\hline Average score & -0.027 & $(0.011)$ & -0.025 & $(0.011)$ & 0.000 \\
\hline Language & -0.027 & $(0.013)$ & -0.025 & $(0.013)$ & 0.000 \\
\hline - below limit & 0.006 & $(0.004)$ & 0.007 & $(0.004)$ & 0.128 \\
\hline Mathematics & -0.028 & $(0.011)$ & -0.025 & $(0.011)$ & 0.000 \\
\hline - below limit & 0.005 & $(0.003)$ & 0.005 & $(0.003)$ & 0.064 \\
\hline \multicolumn{6}{|l|}{ First stage } \\
\hline Offer & -4.430 & $(0.443)$ & -4.224 & $(0.428)$ & 17.760 \\
\hline F-value (instrument) & \multicolumn{2}{|c|}{100.0} & \multicolumn{2}{|c|}{97.4} & \\
\hline
\end{tabular}

Note: Effects are reported as percent of the standard deviation. Standard errors are clustered at the first choice institution level and robust to heteroskedasticity. All regressions control for the risk set by including a full set of dummy variables for each institution by year and the number of child care institutions listed in the application, see Section 3. Control variables are listed in Section 3.

\subsection{Heterogeneous effects of early child care enrollment}

One important argument for why governments want to subsidize child care, is that they can help counter differences in school readiness between children from different socioeconomic backgrounds. It is therefore natural to next consider whether the starting age in child care has a different impact on toddlers from different socioeconomic groups.

Table 7 reports estimates from our IV-model including covariates, for children in different groups. Most strikingly, we find stronger effects among children from low income families. Indeed, among high income families, we find no impact of early child care start on performance in neither language nor mathematics. This suggests that child care policies may be more effective if targeted at low income households. Across other groups, estimates are broadly similar. The exception is parental education, where children from high educated parents are estimated to improve in mathematics from early child care enrollment, while there is no impact among children from low educated parents.

\subsection{Mechanisms}

The effect of child care enrollment is related to the alternative mode of care had the children not been enrolled in child care. In our case, our instrument pushes child care enrollment forward by four months on average, or by about one year for a third of the control group. After this period, children who do not get a lottery offer are also on average enrolled in child care. For both, enrollment in child care is largely an absorbing state, with the vast majority of children who enroll staying enrolled until the school starting age (which is six years in Norway). To understand the drivers behind our estimates, we therefore need to consider these two modes of care. That is, what type of care are control 
Table 7: IV-estimates of the impact of child care starting age on test performance in different subgroups.

\begin{tabular}{lccccccc}
\hline & \multicolumn{3}{c}{ Language } & \multicolumn{3}{c}{ Mathematics } & N \\
& $b$ & $S E$ & Mean & $b$ & SE & Mean & \\
\hline \hline Boys & -0.029 & $(0.018)$ & -0.066 & -0.064 & $(0.019)$ & 0.058 & 996 \\
Girls & -0.025 & $(0.028)$ & 0.065 & -0.057 & $(0.025)$ & -0.057 & 1,014 \\
Parents educ. low & -0.018 & $(0.032)$ & -0.136 & 0.001 & $(0.025)$ & -0.170 & 1,043 \\
Parents educ. high & -0.015 & $(0.009)$ & 0.147 & -0.015 & $(0.014)$ & 0.184 & 967 \\
Family income low & -0.019 & $(0.029)$ & -0.077 & -0.026 & $(0.023)$ & -0.113 & 1,005 \\
Family income high & -0.004 & $(0.013)$ & 0.077 & -0.004 & $(0.016)$ & 0.113 & 1,005 \\
Mom age low & -0.038 & $(0.027)$ & -0.061 & -0.033 & $(0.025)$ & -0.036 & 1,087 \\
Mom age high & -0.010 & $(0.014)$ & 0.072 & -0.033 & $(0.018)$ & 0.042 & 923 \\
\hline
\end{tabular}

Note: Effects are reported as percent of the standard deviation. Standard errors are clustered at the first choice institution level and robust to heteroskedasticity. All regressions control for the risk set by including a full set of dummy variables for each institution by year and the number of child care institutions listed in the application, see Section 3. Control variables are listed in Section 3.

children in before they start regular child care, and what are the characteristics of the formal care that they attend once they do start regular child care.

We start by considering the alternative mode of care that children first attend if they do not get an offer. Typically, one considers three alternatives: Parental care, formal child care and other, more informal, sources of care [Blau and Currie, 2006]. To investigate the alternative mode of care for children who get an offer of a public child care slot, we start by considering survey data on stated demand and actual use for the population of parents with toddlers, presented in Table 8 . While about $70 \%$ of parents state demand for child care, either full time or part time in combination with other forms of care, only $27 \%$ actually have their children enrolled in child care. In comparison, while $56 \%$ of parents say that they care for their children themselves, only $17 \%$ actually prefer to do so. This suggests that parental care is the dominant alternative for Norwegian toddlers in general.

To get an estimate of the importance of parental care as the counterfactual in our particular sample, we now consider the impact of getting an offer of a public child care slot on parents earnings and labor participation. Unfortunately, we do not have data on

Table 8: Survey evidence on the demand for and use of child care.

\begin{tabular}{lcc}
\hline & Stated demand & Actual use \\
\hline \hline Parents & 0.17 & 0.56 \\
Relatives & 0.04 & 0.04 \\
Unlicensed care givers & 0.08 & 0.13 \\
Child care & 0.42 & 0.22 \\
Combined/Other & 0.28 & 0.05 \\
\hline
\end{tabular}

Source: Pedersen [2003]. 
Table 9: Estimates of the impact of a lottery offer on parental labor supply the same year and the next year.

\begin{tabular}{lcccccc}
\hline & \multicolumn{3}{c}{ Application year } & \multicolumn{3}{c}{ Following year } \\
& $b$ & $S E$ & Mean & $b$ & SE & Mean \\
\hline Mother & & & & & & \\
Earnings & 12192 & $(14028)$ & 325032 & 26993 & $(20764)$ & 375982 \\
Employment & -0.012 & $(0.026)$ & 0.902 & 0.006 & $(0.024)$ & 0.910 \\
Full-time eq. & 0.042 & $(0.034)$ & 0.556 & 0.061 & $(0.034)$ & 0.680 \\
Father & & & & & & \\
Earnings & 26986 & $(54388)$ & 634239 & 100367 & $(64988)$ & 676801 \\
Employment & -0.0196 & $(0.018)$ & 0.963 & -0.005 & $(0.0199)$ & 0.969 \\
Full-time eq. & -0.024 & $(0.027)$ & 0.860 & 0.0095 & $(0.0250)$ & 0.881 \\
\hline
\end{tabular}

Note: Effects on earnings are reported in NOK, 1 USD $\approx 6$ NOK. Standard errors are clustered at the first choice institution level and robust to heteroskedasticity. All regressions control for the risk set by including a full set of dummy variables for each institution by year and the number of child care institutions listed in the application, see Section 3. Control variables are listed in Section 3.

hours of work. To measure labor market attachment, we therefore rely on information about annual earnings, including wages and income from self-employment. Specifically, we construct dummy variables for employment based on the basic amounts in the Norwegian Social Insurance Scheme (used to define labor market status, determining eligibility for unemployment benefits as well as disability and old age pension). In 2006, one basic amount was about 80,000 NOK, or about 13,000 USD. Following Havnes and Mogstad [2011a], parents are defined as employed if they earn more than two basic amounts and full time equivalent if they earn more than four basic amounts. Because the child care year starts in August, the impact on parental labor supply may materialize both in the fall of the application year, and in the spring of the following year. We have therefore estimated the impact on outcomes in both years.

Estimates from the reduced form are reported in Table 9. They suggest that receiving a lottery offer increases labor supply of both mothers and fathers. While mothers labor supply increases around the margin of full time employment, fathers labor supply increases mostly at the top. This is consistent with parents responding to the offer by reducing on the extensive margin for mothers and on the intensive margin for fathers, as suggested by anecdotal evidence. This evidence contrasts previous findings for preschool aged children in Norway, where effects on parental labor supply have been estimated to be quite weak [Havnes and Mogstad, 2011a]. This may come as no surprise, since parents of preschool children may both have stronger options in the informal market and be more willing to use them, compared to parents of toddlers. Also, our estimates relate to the mid-2000s, while Havnes and Mogstad [2011a] estimate the impact of the introduction of child care in Norway from the late 1970s. With much higher employment rates of Norwegian women in recent years, informal sources of care may well be less available. 
Next, we investigate whether the characteristics of the child care institution that the child first attends depend on whether the child received a lottery offer or not. If children with offer not only started earlier but also attended better quality child care institutions, then this could be driving the improvement in performance we observed in our main estimates. To evaluate this, Table 10 lists a wide set of characteristics of the child care institutions that children first attend. Structural characteristics are mean test scores of all children who first attended the institution, the child-teacher ratio and travel distance from home. Staff characteristics are mean characteristics of staff, while peer characteristics are mean background characteristics of children in the same institution. In the first four columns of Table 10, we report the means and standard deviations, while the final two columns report reduced form estimates of the impact of a lottery offer on each characteristic. There are few indications that children with offers attended higher quality institutions. On the contrary, children with lottery offers seem to attend institutions with slightly less teachers and adults per child, higher minority shares and larger numbers of children. At the same time the staff and peer composition is largely similar across the two groups. 
Table 10: Characteristics of the first child care institution attended for children with and without a lottery offer

\begin{tabular}{|c|c|c|c|c|c|c|}
\hline & \multicolumn{2}{|c|}{ No offer } & \multicolumn{2}{|c|}{ Offer } & \multicolumn{2}{|c|}{ Red. form } \\
\hline & Mean & $S D$ & Mean & $S D$ & b & SE \\
\hline \multicolumn{7}{|c|}{ Structural characteristics } \\
\hline Language & 98.668 & 6.077 & 98.645 & 5.358 & -0.493 & 0.357 \\
\hline - below limit & 44.427 & 3.766 & 44.772 & 3.139 & 0.128 & 0.230 \\
\hline Mathematics & 0.130 & 0.169 & 0.123 & 0.149 & 0.008 & 0.010 \\
\hline - below limit & 0.083 & 0.141 & 0.067 & 0.102 & -0.013 & 0.010 \\
\hline Children/teacher & 14.732 & 7.968 & 16.950 & 6.102 & 1.309 & 0.675 \\
\hline Distance $(\mathrm{km})$ & 3.206 & 4.031 & 2.315 & 3.559 & -0.535 & 0.293 \\
\hline Distance (min) & 6.215 & 7.239 & 4.330 & 5.864 & -1.066 & 0.543 \\
\hline \multicolumn{7}{|c|}{ Staff characteristics } \\
\hline Income & 249,267 & 41,712 & 261,939 & 26,632 & 13,163 & 3,379 \\
\hline College graduates & 0.361 & 0.155 & 0.3570 & 0.100 & 0.001 & 0.012 \\
\hline Immigrants & 0.233 & 0.193 & 0.2247 & 0.153 & -0.006 & 0.014 \\
\hline Males & 0.110 & 0.115 & 0.1053 & 0.100 & -0.006 & 0.010 \\
\hline Age & 36.913 & 6.354 & 39.2731 & 5.137 & 1.699 & 0.524 \\
\hline \multicolumn{7}{|c|}{ Peer characteristics } \\
\hline Family income & 760,797 & 273,276 & 734,690 & 239,658 & $-23,174$ & 16,747 \\
\hline College graduates & 0.505 & 0.242 & 0.474 & 0.216 & -0.003 & 0.014 \\
\hline Immigrants & 0.074 & 0.117 & 0.088 & 0.124 & 0.010 & 0.007 \\
\hline Males & 0.500 & 0.196 & 0.503 & 0.193 & 0.009 & 0.014 \\
\hline Young & 0.498 & 0.217 & 0.466 & 0.188 & -0.023 & 0.014 \\
\hline
\end{tabular}

Note: Offer are children that received an offer from the assignment lottery, while No offer are children that did not receive an offer from the assignment lottery, see Section 3. Mean reflects average characteristics of the child care center that the child first attends. The first four columns report means and standard deviations. The final two columns report reduced form-estimates from our IV-model, including all covariates and a full set of dummy variables for each institution by year and the number of child care institutions listed in the application, see Section 3.

Finally, to evaluate the plausibility of starting age as a mechanism, we consider childrens performance as a function of the actual starting age separately among children who received a lottery offer and among children who did not receive an offer. In Figure 1 above we saw the cumulative distribution of children having started child care at different ages. Figure 2 reports the mean test score among children who started child care before different ages, approximated by a local linear regression. At the very right of these graphs, the gap between the two groups corresponds to the difference in performance among all treated and all control children, similar to our reduced form effect. As we move left, the treatment and comparison groups are becoming more homogenous in terms of the age at which they start child care. If starting age is an important mechanism, we expect the performance of children to become more similar as starting ages move closer together. This is largely confirmed in both panels: Children who start child care early, whether 


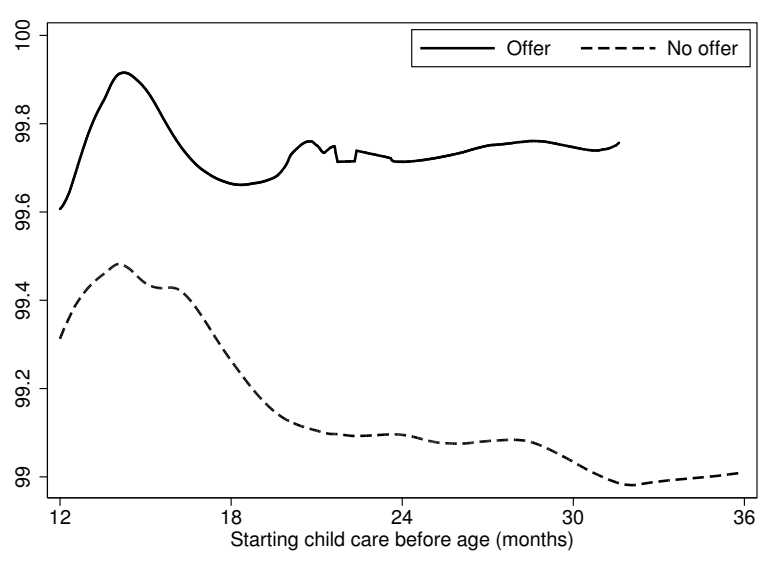

(a) Language

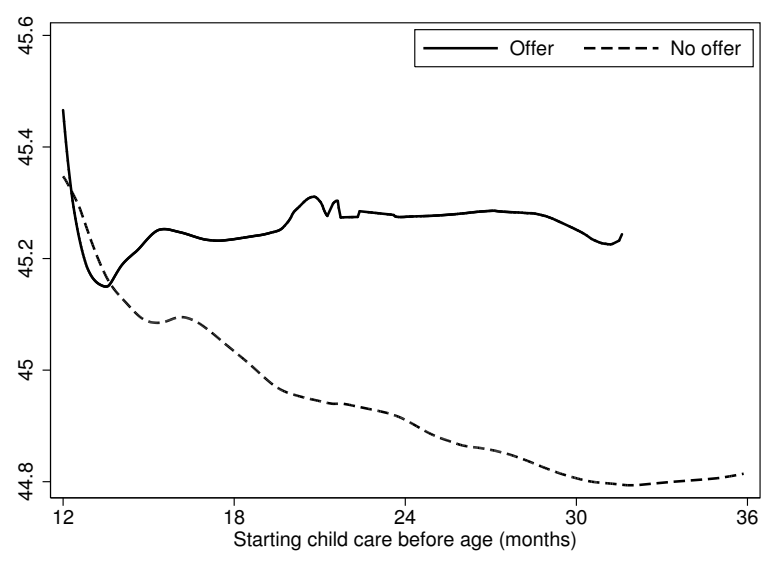

(b) Mathematics

Figure 2: Performance in language and mathematics by child care starting age, for children with and without a lottery offer.

Note: Figures show local linear regression estimates of mean language and mathematics performance against starting age in child care, using an epanichnikov kernel with bandwidth set to one month.

they get a lottery offer or not, perform similarly on the tests, while children who start later and that did not get an offer, tend to perform worse. This is striking in the case of the mathematics test, where the difference between the groups is entirely driven by children in the control group that start late. For the language test, the gap also widens with starting age, but here the gap between early starters suggests that the treatment also generates other relevant differences.

\section{Concluding remarks}

Child care enrollment of young children is substantial and growing, and child care is often heavily subsidized by the government. At the same time, there is concern among both researchers and policymakers that separation from the primary caregiver, typically the mother, may cause stress and anxiety in the child, with potentially adverse effects on childrens development [Bowlby, 1969, Mercer, 2006]. Yet, evidence on how child care affects the development of toddlers is largely missing.

In this paper, we present evidence on the impact of early child care enrollment on the cognitive performance of children at age seven. Results indicate that early child care enrollment has a beneficial effect for children's performance both on a language test and on a mathematics test. Looking across subgroups, we find stronger effects of starting child care early among children from low income families, and no impact among high income families in neither language nor mathematics. This suggests that child care policies may be more effective if targeted at low income households.

Our results on how child care affects the development of toddlers extends the growing 
recent literature on how child care institutions affect the development of preschool age children. While results are mixed, several studies have shown positive effects, in particular for children from disadvantaged families. Our study shows that positive effects of child care are not unique to preschool children, but can be extended also to toddlers below 18 months of age. Importantly, our estimates lend no support to the concerns about detrimental impact of child care at early ages. This is true even though children who are stopped from starting child care early are likely to be at home with a parent.

\section{References}

Atila Abdulkadiroglu, Joshua D. Angrist, Susan M. Dynarski, Thomas J. Kane, and Parag A. Pathak. Accountability and flexibility in public schools: Evidence from boston's charters and pilots. The Quarterly Journal of Economics, 126(2):699-748, 2011. doi: 10.1093/qje/qjr017. URL http://qje.oxfordjournals.org/content/126/2/699.abstract.

Douglas Almond and Janet Currie. Human capital development before age five. NBER Working Papers 15827, National Bureau of Economic Research, Inc, March 2010.

A. B. Atkinson, Lee Rainwater, and Timothy M. Smeeding. Income distribution in OECD countries : evidence from the Luxembourg Income Study. OECD Publications and Information Center, Paris, 1995. ISBN 926414577.

Michael Baker. Innis lecture: Universal early childhood interventions: what is the evidence base? Canadian Journal of Economics, 44(4):1069-1105, November 2011. URL http://ideas.repec.org/a/cje/issued/v44y2011i4p1069-1105.html.

Michael Baker, Jonathan Gruber, and Kevin Milligan. Universal child care, maternal labor supply, and family well-being. The Journal of Political Economy, 116(4):pp. 709-745, 2008. ISSN 00223808.

W. Steven Barnett. Long-term effects of early childhood programs on cognitive and school outcomes. Future of Children, pages 22-50, 1995.

Samuel Berlinski and Sebastian Galiani. The effect of a large expansion of pre-primary school facilities on preschool attendance and maternal employment. Labour Economics, 14(3):665-680, June 2007.

Samuel Berlinski, Sebastian Galiani, and Marco Manacorda. Giving children a better start: Preschool attendance and school-age profiles. Journal of Public Economics, 92(5-6):1416-1440, June 2008. URL http://ideas.repec.org/a/eee/pubeco/v92y2008i5-6p1416-1440.html. 
David Blau and Janet Currie. Pre-School, Day Care, and After-School Care: Who's Minding the Kids?, volume 2 of Handbook of the Economics of Education, chapter 20, pages 1163-1278. Elsevier, 2006.

John Bowlby. Attachment and Loss (Vol 1) Attachment. Hogarth, London, 1969.

Pedro Manuel Carneiro, Katrine V. Løken, and Kjell G. Salvanes. A flying start? maternity leave benefits and long run outcomes of children. Journal of Political Economy, Forthcoming, April 2015.

Elizabeth U. Cascio. Do investments in universal early education pay off? long-term effects of introducing kindergartens into public schools. Working Paper 14951, National Bureau of Economic Research, May 2009.

Flavio Cunha and James J. Heckman. Formulating, identifying and estimating the technology of cognitive and noncognitive skill formation. Journal of Human Resources, 43 (4):738-782, 2008.

Janet Currie. Early childhood education programs. Journal of Economic Perspectives, $15: 213-238,2001$.

Janet Currie and Duncan Thomas. Does head start make a difference? American Economic Review, 85(3):341-364, June 1995.

Phillip DeCicca and Justin Smith. The long-run impacts of early childhood education: Evidence from a failed policy experiment. Economics of Education Review, 36:41-59, 2013.

David Deming. Early childhood intervention and life-cycle skill development: Evidence from head start. American Economic Journal: Applied Economics, 1(3):111-134, 2009.

Nina Drange and Kjetil Telle. Promoting integration of immigrants: Effects of free child care on child enrollment and parental employment. Labour Economics, Fortcoming, 2015.

Christian Dustmann and Uta Schønberg. Expansions in maternity leave coverage and children's long-term outcomes. American Economic Journal: Applied Economics, 4(3):190-224, 2012. doi: 10.1257/app.4.3.190. URL http://www . aeaweb.org/articles.php?doi=10.1257/app.4 .3.190.

Christian Dustmann, Anna Raute, and Uta Schønberg. Does universal childcare matter? evidence from a large expansion in pre-school education. Working paper, University College of London, 2013. 
Christina Felfe and Rafael Lalive. Does early child care help or hurt children's development? IZA Discussion Papers 8484, IZA, 2014.

Christina Felfe, Natalia Nollenberger, and Nuria Rodriguez-Planas. Can't buy mommy's love? universal childcare and children's long-term cognitive development. Journal of Population Economics, 28(2):393-422, 2015.

Maria D. Fitzpatrick. Starting school at four: The effect of universal pre-kindergarten on children's academic achievement. The B.E. Journal of Economic Analysis \& Policy, 8 (1), 2008.

Eliana Garces, Duncan Thomas, and Janet Currie. Longer term effects of head start. Working Paper 8054, National Bureau of Economic Research, December 2000.

Nabanita Datta Gupta and Marianne Simonsen. Non-cognitive child outcomes and universal high quality child care. Journal of Public Economics, 94(1-2): 30 - 43, 2010. ISSN 0047-2727. doi: 10.1016/j.jpubeco.2009.10.001. URL http://www.sciencedirect.com/science/article/pii/S0047272709001169.

Tarjei Havnes and Magne Mogstad. Money for nothing? universal child care and maternal employment. Journal of Public Economics, 95(11-12):1455-1465, 2011a.

Tarjei Havnes and Magne Mogstad. No child left behind. subsidized child care and children's long-run outcomes. American Economic Journal: Economic Policy, 2011b.

Tarjei Havnes and Magne Mogstad. Is universal child care leveling the playing field? Journal of Public Economics, In press, 2014.

Lynn A. Karoly, M. Rebecca Kilburn, and Jill S. Cannon. Early Childhood Interventions: Proven Results, Future Promise. RAND Corporation, Santa Monica, CA, 2005.

Pierre Lefebvre and Philip Merrigan. Family background, family income, cognitive tests scores, behavioural scales and their relationship with post-secondary education participation: Evidence from the nlscy. Cahiers de recherche 0830, CIRPEE, 2008a. URL http://ideas.repec.org/p/lvl/lacicr/0830.html.

Pierre Lefebvre and Philip Merrigan. Child-care policy and the labor supply of mothers with young children: A natural experiment from canada. Journal of Labor Economics, 26(3):519-548, 2008b. doi: 10.1086/587760. URL http://www . journals.uchicago.edu/doi/abs/10.1086/587760.

Qian Liu and Oskar Nordstrom Skans. The duration of paid parental leave and children's scholastic performance. The B.E. Journal of Economic Analysis \&f Policy, 10(1):1-35, January 2010. URL http://ideas.repec.org/a/bpj/bejeap/v10y2010i1n3.html. 
Jens Ludwig and Douglas L. Miller. Does head start improve children's life chances? evidence from a regression discontinuity design. The Quarterly Journal of Economics, 122(1):159-208, 2007. doi: 10.1162/qjec.122.1.159.

Daniela Lundin, Eva Mork, and Bjorn Ockert. How far can reduced childcare prices push female labour supply? Labour Economics, 15(4):647-659, August 2008. URL http://ideas.repec.org/a/eee/labeco/v15y2008i4p647-659.html.

Ruth Hubbell McKey, Larry Condelli, Harriet Ganson, Barbara J. Barrett, Catherine McConkey, and Margaret Plantz. The impact of head start on children, families and communities. final report of the head start evaluation, synthesis and utilization project. Technical report, U.S. Department of Health and Human Services, 1985.

Jean Mercer. Understanding Attachment: Parenting, Child Care, and Emotional Development. Praeger, 2006.

OECD. Starting strong ii: Early childhood education and care. Technical report, 2006.

Department of Education. Kartlegging av tallforståelse og regneferdighet på 1. trinn. laererveiledning. 2011a.

Department of Education. Obligatorisk kartleggingsprøve: Kartlegging av leseferdighet 1. årstrinn del 1: Laererveiledning. 2011b.

Silje Vatne Pedersen. Barnefamiliers tilsynsordninger, yrkesdeltakelse og bruk av kontantstøtte våren 2002. Reports 3, Statistics Norway, 2003.

Christopher J. Ruhm and Jane Waldfogel. Long-Term Effects of Early Childhood Care and Education. SSRN eLibrary, 2011.

Analia Schlosser. Public preschool and the labor supply of arab mothers: Evidence from a natural experiment. Technical report, Mimeo, The Hebrew University of Jerusalem, 2005. 


\section{A Additional material}

\section{A.1 Tables and figures}

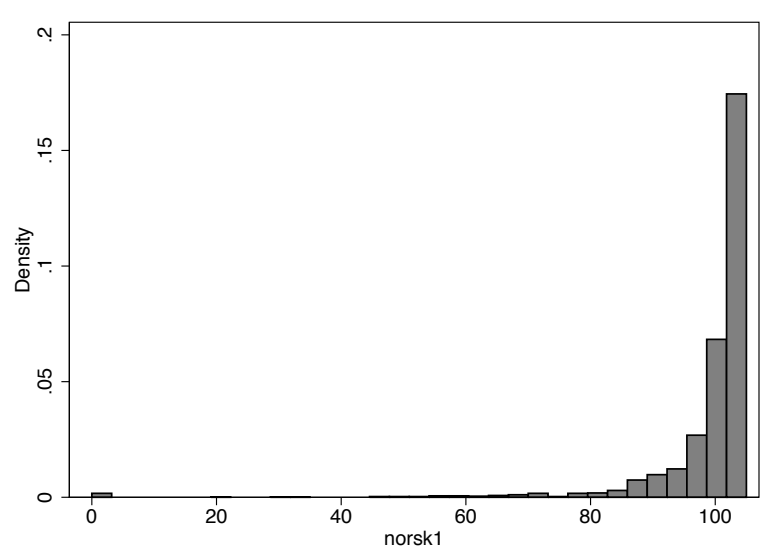

(a) Language

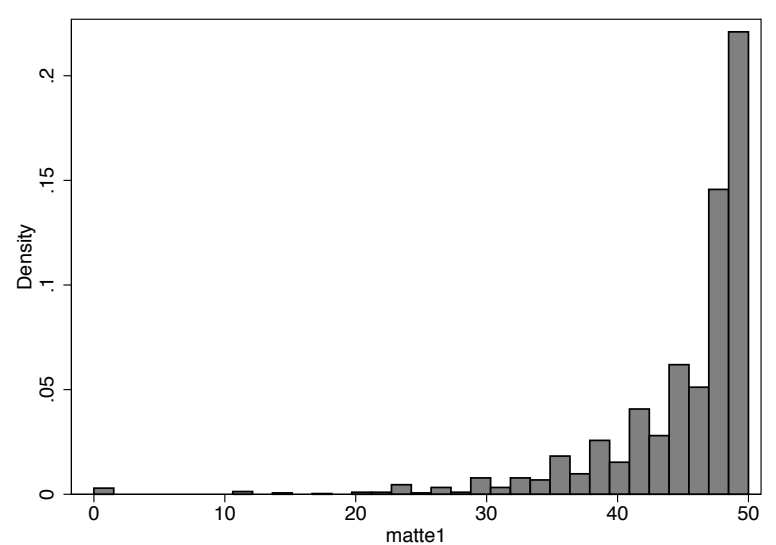

(b) Mathematics

Figure A1: Distribution of test scores.

\section{A.2 Background information about the language test}

Every teacher who is responsible for carrying out tests in his/her class receives a teacher's instruction manual. The following text about the test is from this manual of Education [2011b].

\section{Conditions for learning}

Test part 1: The student's attitude when it comes to reading: This part should provide information about the student's attitude and interests related to different activities related to the written language. Results on this part of the test should not been given a score but is meant as information to the teacher.

\section{Level of knowledge about the alphabet}

Test part 2: To write letters: This measures the student's ability to link sound and letter as well as their ability to construct the letters in question. Firstly, the students hear a word. Secondly the teacher repeats the first sound of the word and asks the students to write the letter that goes with that sound. There is a picture supporting the word in the student book. The students' results on this test should be scored by the teacher.

Test part 3: To recognize letters: This part measures one of the basic skills in reading. Students have four minutes to their disposal. With the starting point a capital letter (versal) the students shall recognize the same lower case letter among several other lower case letters (minuskler). The students' results on this test should be scored by the teacher. 
This test part does not have a "critical threshold" since many students may have been exposed to only one type of letter throughout the first school year. The score registrations are meant as information to the teacher about which of the capital letters and lower case letters the students can recognize and link.

Test part 4: To identify the initial sound: This measure the students' ability to do exactly this. The teacher reads a word and asks the students to identify the first sound of the word and write this down. There is a picture supporting the word in the student book. The students' results on this test should be scored by the teacher.

Test part 5: To draw together sounds: Maps the students' abilities in phonological synthesis. Each part of this test contains a sequence with four pictures that illustrate different words. The teacher instructs the students by firstly presenting the word that illustrate each picture and thereafter the target word, sound by sound, with a break between every sound. The task of the students is to carry through the synthesis process and determine which picture that goes with the target word. The students' results on this test should be scored by the teacher.

\section{Understanding words}

Test part 6: To write words: Consists of a word dictation where each word is presented for the students in a sentence. This test part comprises 8 sentences in total. The students' results on this test should be scored by the teacher.

Test part 7: To read words implies that the students should compare an illustration with four written words and subsequently identify the word that fits with the illustration. The students should identify as many word as possible (total possible words 19) within five minutes. The students' results on this test should be scored by the teacher.

\section{Understanding sentences}

Test part 8: To read sentences consists of nine sub-parts. In each part the student reads a sentence and mark the picture that illustrates the entire content of the sentence among four alternative pictures with similar content. The length of the sentences increases from two to five words as the test proceeds. The students should link as many pictures and sentences as possible within five minutes. The students' results on this test should be scored by the teacher.

\section{A.3 Background information about the mathematics test}

Every teacher responsible for carrying out tests in his/her class receives a teacher's instruction manual. The following text about the test is from this manual of Education [2011a]. 
This test consists of nine pages with several different tasks (se below). The points scored on each page should be added together. The critical threshold for the mathematics test is based on the aggregated sum of points.

Page 1: Maps the students' ability to count, as well as if they know the numbers and can link a number of items to a certain figure

Page 2: Maps if the students understand the idea "equally many", i.e. that they can compare the number in two different countable sets

Page 3: Investigates if the students' can rank the numbers in two different countable sets and if they understand the concept "most"

Figure A2: Page 3

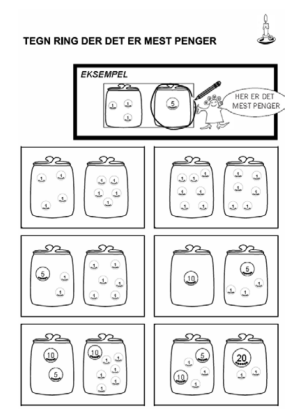

Page 4: Maps the students' knowledge about a sequence of numbers (linear)

Page 5: Maps the students' knowledge about a sequence of numbers (linear), if they can count forward and backward from a given number, and if they understand the sequence concepts "prior to" and "subsequent to"

Page 6: Investigates the students' knowledge of a series of numbers and the ranking of given numbers within the series

Page 7: Tests the students' ability to split a number into two other numbers (i.e. $4=1+\ldots)$

Page 8: Tests the students' ability to solve text assignments. The assignments have different additive structures and they deal with both addition and subtraction (but rather low numbers)

Page 9: Maps the students' ability to add two numbers. The additive structure deal with the combination of two sums of money, to allow the students to employ their knowledge about money and coins to arrive at the correct answer 